\title{
Stable Isotope Labeling Tandem \\ Mass Spectrometry (SILT) to Quantify \\ Protein Production and Clearance Rates
}

\author{
Randall J. Bateman, ${ }^{\mathrm{a}, \mathrm{d}, \mathrm{e}}$ Ling Y. Munsell, ${ }^{\mathrm{b}}$ Xianghong Chen, \\ David M. Holtzman, ${ }^{\mathrm{a}, \mathrm{c}, \mathrm{d}, \mathrm{e}}$ and Kevin E. Yarasheski ${ }^{\mathrm{b}}$ \\ a Department of Neurology, Washington University School of Medicine, St. Louis, Missouri, USA \\ ${ }^{\mathrm{b}}$ Department of Medicine, Washington University School of Medicine, St. Louis, Missouri, USA \\ c Department of Molecular Biology and Pharmacology, Washington University School of Medicine, St. Louis, \\ Missouri, USA \\ d Hope Center for Neurological Disorders, Washington University School of Medicine, St. Louis, Missouri, \\ USA \\ e Alzheimer's Disease Research Center, Washington University School of Medicine, St. Louis, Missouri, USA
}

In all biological systems, protein amount is a function of the rate of production and clearance. The speed of a response to a disturbance in protein homeostasis is determined by turnover rate. Quantifying alterations in protein synthesis and clearance rates is vital to understanding disease pathogenesis (e.g., aging, inflammation). No methods currently exist for quantifying production and clearance rates of low-abundance (femtomole) proteins in vivo. We describe a novel, mass spectrometry-based method for quantitating low-abundance protein synthesis and clearance rates in vitro and in vivo in animals and humans. The utility of this method is demonstrated with amyloid- $\beta(\mathrm{A} \beta)$, an important low-abundance protein involved in Alzheimer's disease pathogenesis. We used in vivo stable isotope labeling, immunoprecipitation of $\mathrm{A} \beta$ from cerebrospinal fluid, and quantitative liquid chromatography electrospray-ionization tandem mass spectrometry (LC-ESI-tandem MS) to quantify human A $\beta$ protein production and clearance rates. The method is sensitive and specific for stable isotope-labeled amino acid incorporation into CNS $\mathrm{A} \beta$ ( $\pm 1 \%$ accuracy). This in vivo method can be used to identify pathophysiologic changes in protein metabolism and may serve as a biomarker for monitoring disease risk, progression, or response to novel therapeutic agents. The technique is adaptable to other macromolecules, such as carbohydrates or lipids. (J Am Soc Mass Spectrom 2007, 18, 997-1006) @ 2007 American Society for Mass Spectrometry

$\mathrm{R}$ ecent advances in mass spectrometry have led to significant improvements in the types and complexity of samples that can be analyzed, sensitivity of detection, and amount of structural information that can be obtained. These advances have been combined with chemical and isotope labeling techniques that allow for the comparison of protein amounts under different experimental conditions [1, 2]. SILAC (stable isotope labeling by amino acids in cell culture), a technique used to label proteins expressed in vitro by incubating cells with stable isotope-labeled amino acids, provides an excellent non-radioactive method for labeling proteins during production that does not alter chemical or biologic properties [3]. This in vitro labeling method has been used with liquid chromatography mass spectrometry (LC-MS) to obtain mea-

The authors declare that there is a pending application for patent of some of the methods described in this article.

Address reprint requests to Dr. Randall J. Bateman, Department of Neurology, Washington University School of Medicine, 660 S. Euclid, Box 8111, St. Louis, MO 63110. E-mail: batemanr@wustl.edu surements of relative and total amounts of low-abundance proteins. In addition, stable isotope labeling has also been used in vivo to produce highly enriched protein/peptide internal standards for proteomic analysis [4].

Techniques to measure stable isotope incorporation in vivo have used gas chromatography mass spectrometry (GC-MS), which has high mass resolution, but low sensitivity, and so requires a relatively large amount of protein for quantitative analysis. In addition, GC-MS quantifies stable isotope enrichment of amino acids and does not provide specific identification of the source proteins/peptides. Human plasma and skeletal muscle protein synthesis rates have been quantified using this method, although only the most abundant proteins have been studied [5]. Most proteins in biologic samples are present in less than nanomole per milliliter quantities and approach the limit of detection for most GC-MS systems.

We describe a novel method for quantifying production and clearance rates for low-abundance (femtomole) proteins using tandem mass spectrometry (MS/MS). By 
using MS/MS ions for isotope ratio quantitation, rather than the parent MS ion, significantly higher signal-tonoise ratio can be achieved. This allows for isotope ratio quantitation for low-abundance proteins/peptides that would not be detectable by standard MS analysis. The technique uses in vivo rates of stable isotope-labeled amino acid incorporation and tandem MS quantitation, so that protein production and clearance rates are calculated while peptide sequence information is obtained for positive protein identification.

Protein production and clearance rates are important parameters that are tightly regulated under normal physiologic and pathophysiologic conditions [6-11]. Certain disease states are characterized by disturbances in protein production, accumulation, or clearance. For example, CNS diseases such as Alzheimer's disease, frontal temporal dementia, Huntington disease, and Creutzfeldt-Jakob disease are associated with disturbance in $\mathrm{A} \beta$, tau, huntingtin, and prion proteins, respectively. The amyloid hypothesis proposes that disturbances in the metabolism of amyloid- $\beta$ (A $\beta$ ) [12] causes Alzheimer disease (AD). $A \beta$ is normally made predominantly by neurons and is present in cerebrospinal fluid and blood, although no methods were available to quantify $\mathrm{A} \beta$ synthesis or clearance rates in humans. To address critical questions about underlying AD pathogenesis and $\mathrm{A} \beta$ metabolism in humans, we developed a method to quantify $\mathrm{A} \beta$ fractional synthesis rate (FSR) and fractional clearance rate (FCR) in vivo in the CNS of humans. The findings indicate that reproducible rates of $\mathrm{A} \beta$ synthesis and clearance can be quantified in normal humans by administering stable isotope-labeled amino acids $\left({ }^{13} \mathrm{C}_{6}\right.$-leucine), sampling CSF, and using LC-ESI-tandem MS to quantify the amount and kinetics of ${ }^{13} \mathrm{C}_{6}$-leucine labeling in $\mathrm{A} \beta$ [13].

The current method was developed to measure the production and clearance rate of $A \beta$ in humans, but is applicable to proteins being produced in vitro or in vivo because all proteins are labeled simultaneously. This communication describes the methodology to perform quantitative measurements of proteins by stable isotope labeling and tandem mass spectrometry (SILT) and expands the technique to use two stable isotope-labeled amino acids to measure the production rate sequentially in the same subject.

\section{Methods}

\section{Materials}

${ }^{13} \mathrm{C}_{6}$-Leucine $\left(98 \%{ }^{13} \mathrm{C}_{6}\right)$ and ${ }^{13} \mathrm{C}_{6}$-phenylalanine $(95 \%$ ${ }^{13} \mathrm{C}_{6}$ ) were obtained from Cambridge Isotope Laboratories (Andover, MA, USA). M266 antibody against $\mathrm{A} \beta$ was provided by Eli Lilly (Indianapolis, IN, USA). $\mathrm{CNBr}$-activated sepharose $4 \mathrm{~B}$ beads were obtained from Amersham Biosciences (Piscataway, NJ, USA). Formic acid $(98 \%)$ and ammonium bicarbonate (ultra $>99.5 \%$,) were obtained from Fluka (AG, Buchs, Switzerland). Fetal bovine serum (FBS) and Dulbecco's modified essential media (DMEM), with and without leucine, were obtained from the Washington University Tissue Culture Support Center. Hygromycin B, Streptomyces sp. \#400051 was obtained from EMD Biosciences (San Diego, CA, USA) and made in $100 \times$ stock of $426 \mathrm{mg} / \mathrm{mL}$; Blasticidin S, Hydrochloride (Streptomyces griseochromogenes \#203350) obtained from CalBioChem (San Diego, CA, USA) and made in $100 \times$ stocks of $10 \mathrm{mg} / \mathrm{mL}$. Sequence grade modified trypsin was obtained from Promega (Madison, WI, USA).

\section{Cell Culture and In Vitro Labeling}

Human neuroglioma cells that produce $\mathrm{A} \beta[14]^{\circ}$ were grown in the presence of ${ }^{13} \mathrm{C}_{6}$-leucine or unlabeled leucine. The unlabeled media was DMEM + 10\% FBS + antibiotics. The labeled media was leucine-free DMEM $+105 \mathrm{mg} / \mathrm{L}{ }^{13} \mathrm{C}_{6}$-leucine $+3 \mathrm{kDa}$ dialyzed FBS + antibiotics. Media was collected every $24-48 \mathrm{~h}$ of incubation to obtain highly labeled or unlabeled $A \beta$. The media was pooled separately and stored at $-20{ }^{\circ} \mathrm{C}$. $\mathrm{A} \beta$ concentration in each pool was determined by ELISA $^{\circ}[15] .{ }^{\circ}{ }^{\circ}$ sing $^{\circ}$ serial, ${ }^{\circ}$ volumetric ${ }^{\circ}$ dilution ${ }^{\circ}$ of ${ }^{\circ}$ labeled and unlabeled media, ${ }^{13} \mathrm{C}_{6}-\mathrm{A} \beta$ enrichment standards of $20,10,5,2.5,1.25$, and $0 \%$ labeled media were made, aliquoted, and stored at $-80^{\circ} \mathrm{C}$.

\section{Amyloid- $\beta$ Immunoprecipitation}

Antibody beads were prepared by covalently binding m266 antibody to CNBr sepharose beads according to the manufacturer's protocol at a concentration of 10 $\mathrm{mg} / \mathrm{mL} \mathrm{m} 266$ antibody. The antibody beads were stored at $4{ }^{\circ} \mathrm{C}$ in a $50 \%$ slurry of PBS $0.02 \%$ azide.

The immunoprecipitation mixture was $250 \mu \mathrm{L}$ of $5 \times$ RIPA, $12.5 \mu \mathrm{L}$ of $100 \times$ protease inhibitors, and $30 \mu \mathrm{L}$ of antibody-bead slurry added to $1 \mathrm{~mL}$ of sample in an Eppendorf micro-centrifuge tube which was rotated overnight at $4{ }^{\circ} \mathrm{C}$. The beads were rinsed once with $1 \times$ RIPA and twice with $1 \times$ ammonium bicarbonate. They were aspirated dry after the final rinse and $\mathrm{A} \beta$ was eluted off the antibody-bead complex using $30 \mu \mathrm{L}$ of $100 \%$ formic acid. After centrifuging the beads again, the formic acid supernatant was transferred to a new Eppendorf tube and evaporated in a Savant speed-vac (model AES2010) for $15 \mathrm{~min}$ at low rate (ambient temperature) with radiant cover and full vacuum, followed by $30 \mathrm{~min}$ at medium rate $\left(43^{\circ} \mathrm{C}\right)$ with radiant cover and full vacuum. The sample was reconstituted in $5 \mu \mathrm{L}$ of acetonitrile and $20 \mu \mathrm{L}$ of $25 \mathrm{mM}$ ammonium bicarbonate, $\mathrm{pH}$ 8.0. The sample was digested with 400 ng sequence grade trypsin and incubated at $37^{\circ} \mathrm{C}$ for $16 \mathrm{~h}$.

\section{Liquid Chromatography/Mass Spectrometry}

LCQ ESI-tandem MS was performed on a ThermoFinnigan (San Jose, CA, USA) LCQ-DECA equipped with an electrospray ionization source. The LCQ-DECA was operated in the positive ion mode using a spray 
voltage of $5 \mathrm{kV}$, a capillary voltage of $7 \mathrm{~V}$, and a capillary temperature at $200{ }^{\circ} \mathrm{C}$. The instrument settings were set for ion-specific analysis at full MS/MS mode at $28 \%$ normal collisional energy of the precursor MS ions at $m / z=663.5$ and 666.5 (doubly charged $[\mathrm{M}+2 \mathrm{H}]^{+2}$ ). Mass spectra were collected over a 38-min period after a 10-min delay time.

The liquid chromatography for LCQ analysis was carried out on a Waters (Milford, MA, USA) microcapillary liquid chromatography system with autoinjector interfaced to the mass spectrometer. Samples were chilled at $5{ }^{\circ} \mathrm{C}$ until injection. A $5-\mu \mathrm{L}$ aliquot of each sample was injected on-column to a Vydac $\mathrm{C}_{18}$ capillary column $(0.3 \times 150 \mathrm{~mm}$ MS $5 \mu \mathrm{m})$. The HPLC gradient of $0-90 \% \mathrm{~B}(0-5 \mathrm{~min}$ at $0 \% \mathrm{~B}, 5-25 \mathrm{~min}$ to $50 \%$ $\mathrm{B}, 25-30 \mathrm{~min}$ to $90 \% \mathrm{~B}, 30-33 \mathrm{~min}$ at $90 \% \mathrm{~B}, 33-35 \mathrm{~min}$ to $0 \% \mathrm{~B}, 35-40 \mathrm{~min}$ at $0 \% \mathrm{~B})$ over $40 \mathrm{~min}(\mathrm{~A}=0.1 \%$ formic acid in water, $\mathrm{B}=0.1 \%$ formic acid in $80 \%$ acetonitrile $/ 20 \%$ water) at a flow rate of $6 \mu \mathrm{L} / \mathrm{min}$ was used.

LTQ experiments were performed on a ThermoFinnigan LTQ equipped with a New Objective (Woburn, MA, USA) nanoflow electrospray ionization source. Sample injection and LC gradients were controlled by an Eksigent 2D-LC nanoflow pump operating in a 1D mode. Samples were chilled at $5^{\circ} \mathrm{C}$ until injection. A 5- $\mu \mathrm{L}$ aliquot of each sample was injected on-column to a New Objective biobasic picofrit column (75 $\mu \mathrm{m} \times 150 \mathrm{~mm})$. The HPLC gradient used was: $5-95 \% \mathrm{~B}(0-5 \mathrm{~min}$ at 5\% B, 5-45 $\mathrm{min}$ to $50 \% \mathrm{~B}, 45-50$ $\min$ to $90 \% \mathrm{~B}, 50-60 \mathrm{~min}$ to $5 \% \mathrm{~B}$ ), over $60 \mathrm{~min}(\mathrm{~A}=$ $0.1 \%$ formic acid in water, $\mathrm{B}=0.1 \%$ formic acid in $80 \%$ acetonitrile/20\% water) at a flow rate of $200 \mathrm{~nL} / \mathrm{min}$. The LTQ was operated in the positive-ion mode using a spray voltage of $1.7 \mathrm{kV}$ and a capillary temperature of $220^{\circ} \mathrm{C}$. The MS/MS scanning was performed as an ion-specific experiment with data-independent scans for full MS and MS/MS scans of unlabeled and labeled precursor ions. The instrument settings were $28 \%$ normal collisional energy of the precursor MS ions at $\mathrm{m} / \mathrm{z}=$ 663.5 and 666.5 (doubly charged species $[\mathrm{M}+2 \mathrm{H}]^{+2}$ ) with an isolation width of 2.5 Daltons. Mass spectra were collected over an 80-min period.

\section{Gas Chromatography-Mass Spectrometry}

As described, ${ }^{13} \mathrm{C}_{6}$-enrichment in plasma and CSF leucine, ketoisocaproic acid (KIC), and phenylalanine were quantified using capillary gas chromatographymass spectrometry (GC-MS; Agilent $6890 \mathrm{~N}$ gas chromatograph and Agilent 5973N mass selective detector, Palo $^{\circ}$ Alto, $\left.{ }^{\circ} \mathrm{CA},{ }^{\circ} \mathrm{USA}\right)^{\circ}[16] .{ }^{\circ}$ Leucine $^{\circ}$ and ${ }^{\circ}$ phenylalanine were converted to their heptafluorobutyric propyl ester derivatives; ${ }^{13} \mathrm{C}_{6}$-leucine $(\mathrm{m} / \mathrm{z} 349$ and 355$)$ and ${ }^{13} \mathrm{C}_{6}$-phenylalanine $(\mathrm{m} / \mathrm{z} 383$ and 389$)$ enrichments were quantified using GC-MS in negative chemical ionization mode. In the same plasma samples, KIC was isolated, the trimethylsilyl quinoxalinol derivative was formed, and ${ }^{13} \mathrm{C}_{6}$ enrichment was quantified using
GC-positive chemical ionization-MS and selected ion monitoring $^{\circ}\left(m / z 275^{\circ} \text { and }^{\circ} 281\right)^{\circ}[16] .{ }^{\circ}$ The $^{\circ} \mathrm{GC}-\mathrm{MS}^{\circ}$ instrument response was calibrated using gravimetric standards of known isotope enrichment.

\section{Calculation of Labeled Protein Ratio}

Percentage labeled $\mathrm{A} \beta$ was calculated as the ratio of all $\mathrm{b}$ - and $\mathrm{y}$-tandem MS ion intensities from $\mathrm{A} \beta^{*}{ }_{17-28}$ $(m / z=666.5)$ divided by all $b$ - and $\mathbf{y}$-tandem MS ion intensities from $\mathrm{A} \beta_{17-28}(m / z=663.5)$. A custom Microsoft Excel spreadsheet with macros (available upon request) was used to sum all b- and $y$-series ion intensities, calculate the isotope ratios, and plot the labeled $\mathrm{A} \beta$ curves. Specifically, these calculations were performed by copying the unlabeled and labeled tandem MS spectra signal intensities averaged over the elution peak directly from Xcalibur into the custom Excel spreadsheet. The spreadsheet parsed the data to identify and sum the signal intensities from predicted unlabeled and labeled $\mathrm{b}$ and $\mathrm{y}$ ions, and divided labeled to unlabeled ion intensities to produce a ratio for that dataset. The ratio was calculated after summing all ion intensities for labeled and unlabeled tandem MS ions. Only the $\mathrm{M}_{0}$ (the most abundant for this peptide) and $\mathrm{M}_{6}$ ions were used for calculations. The labeled ratio for each dataset and a standard curve were plotted automatically.

\section{Participants and Sampling}

All human studies were approved by the Washington University Human Studies Committee and the General Clinical Research Center Advisory Board. Verbal and written informed consents were obtained from the participant.

\section{Results}

Quantitation of newly synthesized proteins using stable isotope-labeled amino acids consisted of five basic steps: (1) Label proteins by application and incorporation of stable isotope labeled amino acid(s); (2) isolate and concentrate the protein of interest from other labeled proteins, by immunoprecipitation or another method; (3) proteolytically cleave the protein into smaller peptide fragments; (4) use tandem mass spectrometry to quantitate the relative amounts of labeled and unlabeled peptide fragments; and (5) calculate the amount of unlabeled and labeled tandem MS ions (Figure ${ }^{\circ}$ ).

\section{In Vitro Labeling and Quantitation}

We labeled newly synthesized $\mathrm{A} \beta$ in vitro by incubating $^{\circ}$ neuroglioma ${ }^{\circ}$ cells ${ }^{\circ}[14]^{\circ}$ with ${ }^{\circ 13} \mathrm{C}_{6}$-leucine added to leucine-free media. This stable isotope-labeled amino acid was chosen because it equilibrates across the

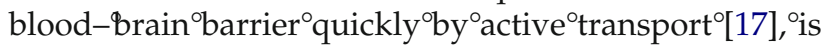


an essential amino acid, is present in $\mathrm{A} \beta$ protein, and is safe and non-radioactive. Labeling a protein with carbon-13 does not significantly change its chemical or biologic properties because entire organisms have been grown on pure carbon-13 substrates/media without any $^{\circ}$ deleterious ${ }^{\circ}$ effect $^{\circ}$ [18]. ${ }^{\circ}$ Stable $^{\circ}$ isotope-labeled leucine was incorporated into $\mathrm{A} \beta$ at amino acid positions 17 and 34.

Under these in vitro incubation conditions, all leucine-containing proteins synthesized are labeled. The protein of interest, $\mathrm{A} \beta$, was isolated and concentrated, using immunoprecipitation techniques. In CSF and neuroglioma cell culture conditions, $A \beta$ is present in low picomole amounts per milliliter. Immunoprecipitation conditions for unlabeled $\mathrm{A} \beta$ were tested and refined using archived human CSF and cell culture media. A $\beta$ was immunoprecipitated from samples of human CSF or cell culture media using an A $\beta$-specific monoclonal antibody (m266; provided by Eli Lilly) covalently linked to cyanogen bromide Sepharose beads. A $\beta$ was eluted from the antibody-bead complex using formic acid, and directly identified and characterized using matrix assisted laser desorption ionization time of flight (MALDI-TOF) mass spectrometry. Mass spectra for $\mathrm{A} \beta$ were similar to previously published findings ${ }^{\circ}[19]^{\circ}\left(\right.$ Figure $\left.^{\circ} 2 \mathrm{a}\right)$.

Naturally occurring isotopes, including ${ }^{13} \mathrm{C}(1.1 \%$ of all carbon), cause a distribution of masses of larger molecules, including proteins. Because of the size of $\mathrm{A} \beta$

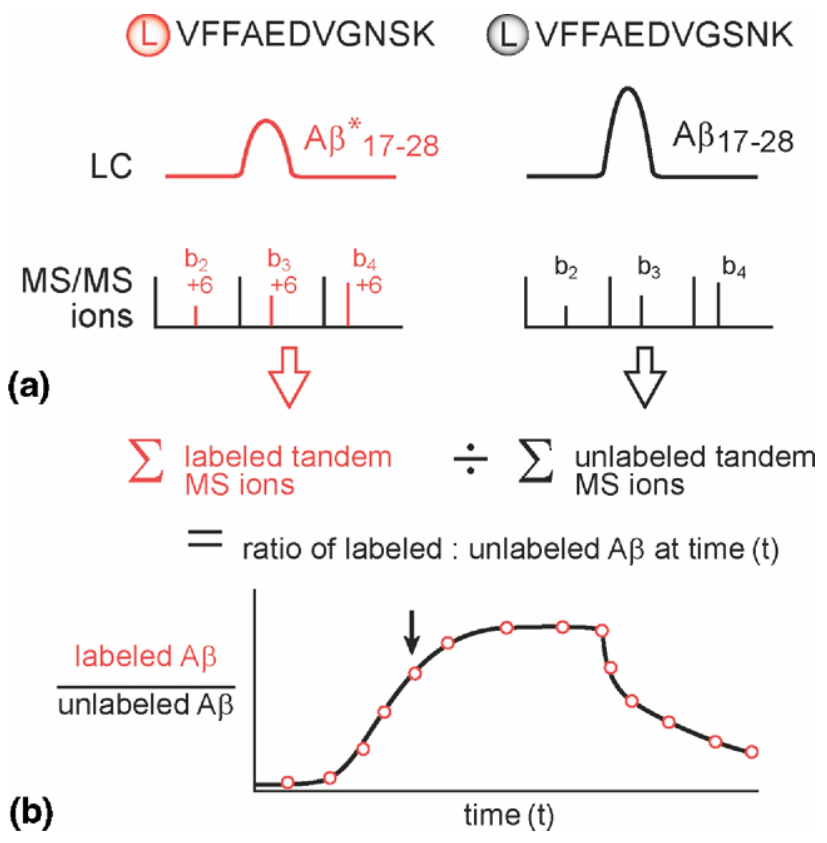

Figure 1. Quantitation by tandem mass spectrometry (MS/MS) of amino acid stable isotope labeling of newly synthesized proteins: (a) Trypsin fragments of the protein are separated and concentrated using liquid chromatography before MS for detection and quantification of both labeled and unlabeled fragments using MS/MS ions. (b) Diagram of quantitation of labeled and unlabeled $\mathrm{A} \beta_{17-28}$ and graph of labeling curve to calculate synthesis and clearance rates of proteins.
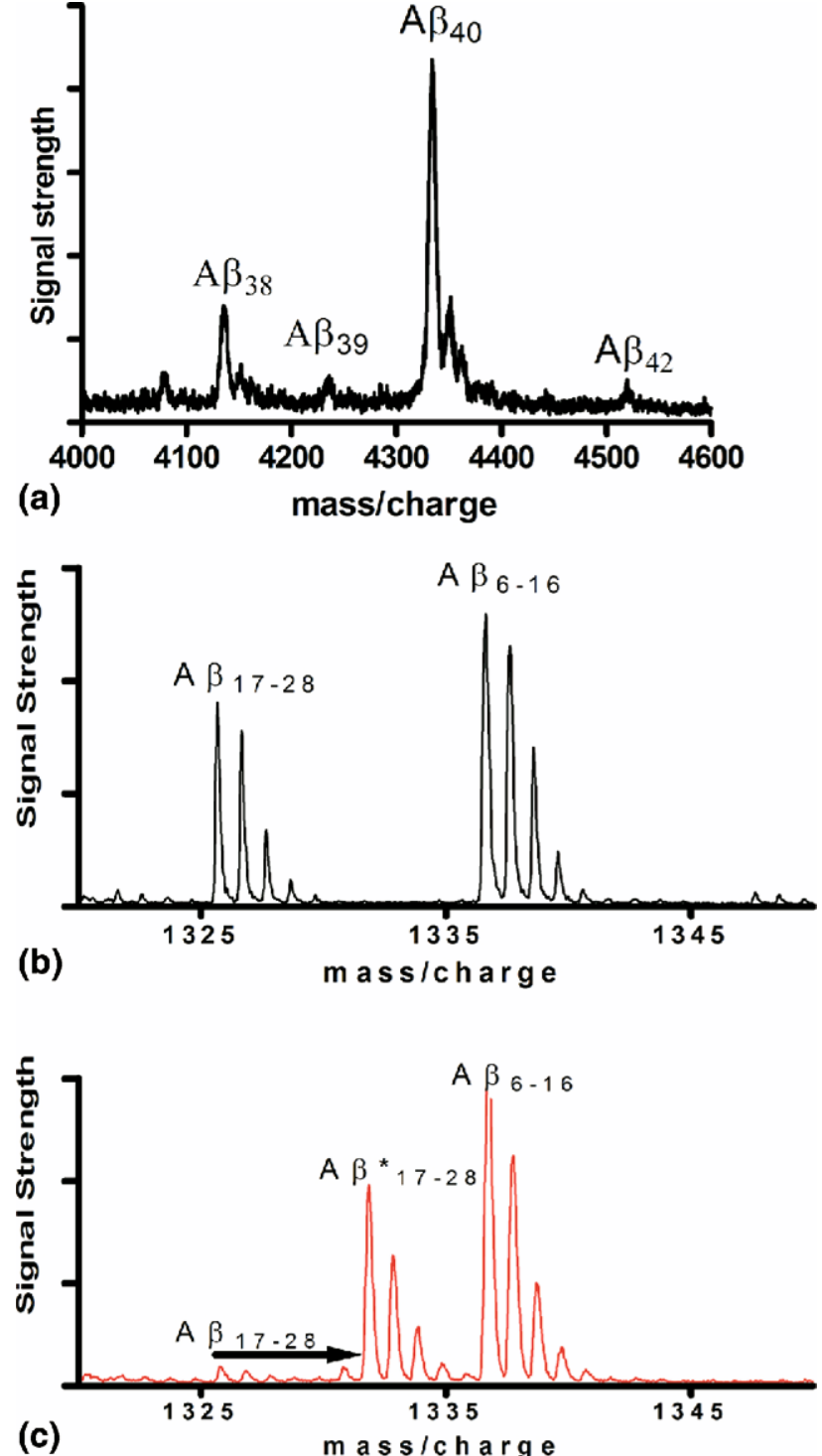

Figure 2. MALDI-TOF qualitative analysis of $A \beta$. (a) $\mathrm{A} \beta$ peptides were immunoprecipitated from human CSF with the central domain anti-A $\beta$ antibody, m266, directed against amino acids 13-28. After immunoprecipitation, $\mathrm{A} \beta$ was eluted with $100 \%$ formic acid and analyzed on a MALDI-TOF mass spectrometer. Mass spectral peaks are noted with their corresponding peptide variants; $\mathrm{A} \beta_{38}, \mathrm{~A} \beta_{39}, \mathrm{~A} \beta_{40}$, and $\mathrm{A} \beta_{42}$. The level of $\mathrm{A} \beta_{42}$ was approximately $10 \%$ of $\mathrm{A} \beta_{40}$ levels, as previously reported in human CSF. (b) Unlabeled media from a human neuroglioma cell line producing $\mathrm{A} \beta$ in vitro was collected and immunoprecipitated. $\mathrm{A} \beta$ peptides were then cleaved with trypsin at sites 5,16 , and 28 producing the two fragment envelopes shown at masses 1325 and 1336. Note the two mass envelopes of $A \beta$ fragments $A \beta_{17-28}$ (1325) and $\mathrm{A} \beta_{6-16}$ (1336) showing the statistical distribution of natural isotopes in unlabeled $A \beta$. (c) Human neuroglioma cells were cultured for $24 \mathrm{~h}$ in the presence of ${ }^{13} \mathrm{C}_{6}$-leucine. Media was collected and $\mathrm{A} \beta$ was immunoprecipitated. $\mathrm{A} \beta$ peptides were then cleaved with trypsin at sites 5,16 , and 28 producing the fragment envelopes shown at masses 1325,1331 , and 1336. Note the shift of mass (arrow) of $\mathrm{A} \beta_{17-28}$ from 1325 to 1331 that demonstrates the ${ }^{13} \mathrm{C}_{6}$-leucine label. $\mathrm{A} \beta_{6-16}$ does not contain a leucine and so is not labeled or mass shifted. A minor amount of $\mathrm{A} \beta_{17-28}$ remains unlabeled. 


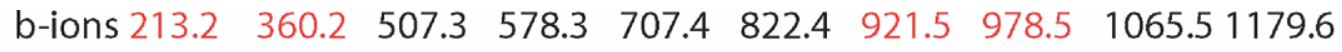
LV
$\mathrm{F} \quad \mathrm{F}$
A $\quad E$
E D
$\mathrm{V}$
G
$\mathrm{S} \quad \mathrm{N} \quad \mathrm{K}$

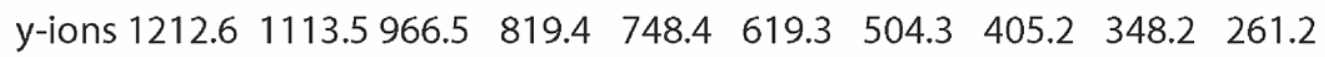
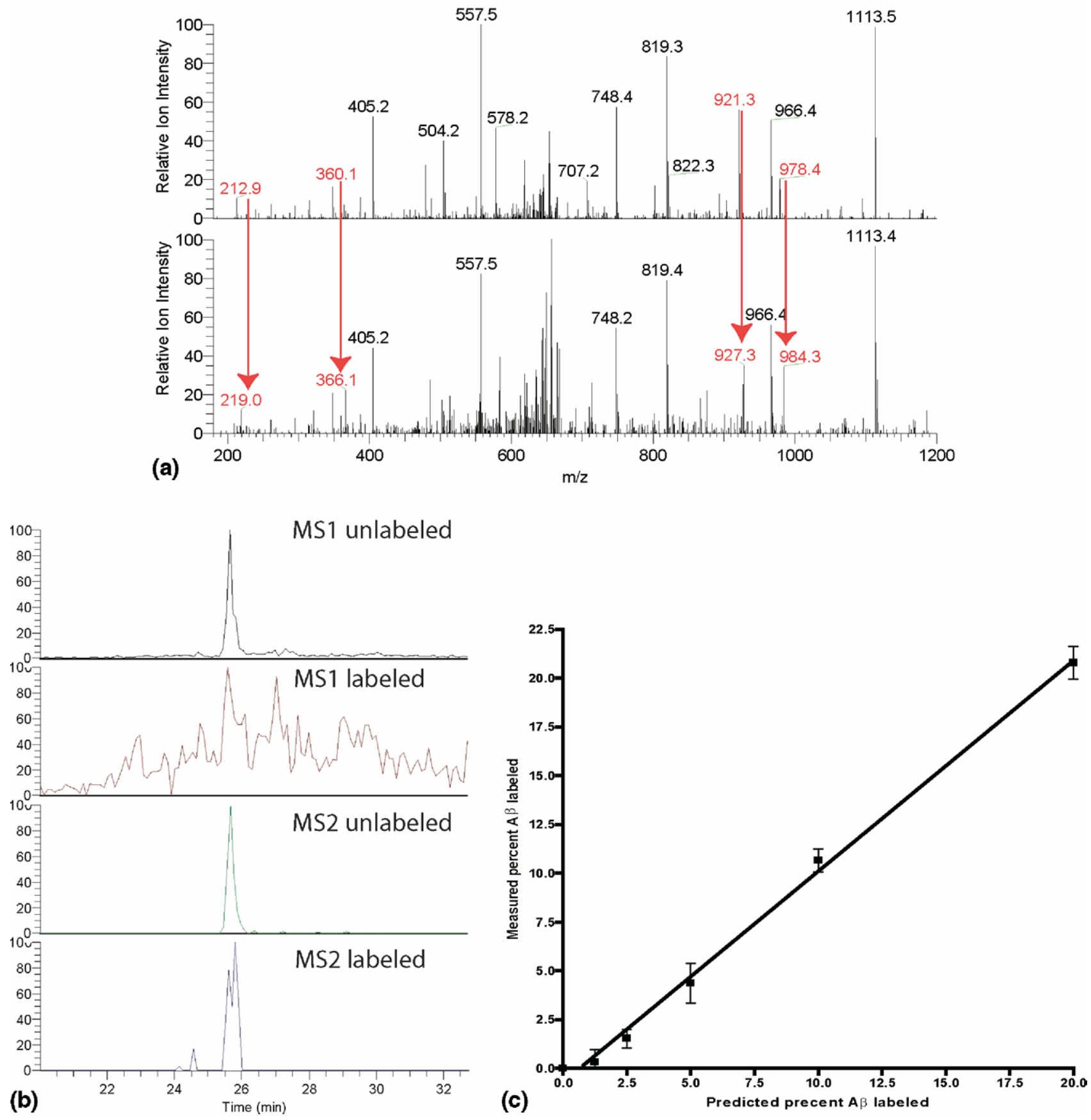

Figure 3. LCQ quantitation of MS/MS spectra of in vitro unlabeled and labeled $\mathrm{A} \beta_{17-28}$. (a) Neuroglioma cell media that was unlabeled (top) or labeled (bottom) with ${ }^{13} \mathrm{C}_{6}$-leucine. The spectra were obtained using MS/MS analysis of unlabeled parent ion $\mathrm{A} \beta_{17-28}(\mathrm{~m}=1325)$ or labeled parent ion $\mathrm{A} \beta_{17-28}(\mathrm{~m}=1331)$ by LCQ-ESI-MS. Note the tandem MS ions containing leucine at $\mathrm{A} \beta_{17}$ (see masses $213,360,921$, and 978) are mass shifted by 6 Daltons demonstrating the labeled leucine (arrows). The $\mathrm{A} \beta$ ions without leucine are not labeled and are not mass shifted by 6 Daltons (see mass 348.2 and 405.3 in both spectra). (b) Base peak chromatograms of MS1 versus MS2 quantitation. In the same MS run after immunoprecipitation and trypsin digestion of A $\beta 2.5 \%$ leucine-labeled culture was analyzed. Reconstructed base peak chromatograms demonstrate the signal-to-noise ratio improvements of MS2 versus MS1 quantitation. (c) Standard curve of labeled $\mathrm{A} \beta$ to unlabeled $\mathrm{A} \beta$. Labeled cultured media was serially diluted with unlabeled media to generate samples for a standard curve. A $\beta$ was immunoprecipitated from the media, trypsin digested, and $A \beta_{17-28}$ fragments were analyzed on a LCQ-ESI-MS and the tandem mass spectra ions were quantitated using custom-written software. The predicted percentage labeled $\mathrm{A} \beta$ versus the measured value is shown with a linear regression line. 
and the presence of these naturally occurring isotopes, $\mathrm{A} \beta$ was enzymatically cleaved into fragments $\left(\mathrm{A} \beta_{1-5}\right.$, $\mathrm{A} \beta_{6-16}, \mathrm{~A} \beta_{17-28}$, and $\mathrm{A} \beta_{29-40 / 42}$ ) using trypsin, before mass spectrometry analysis. The $A \beta_{17-28}$ fragment has a nominal mass of 1324.6 Daltons (D), contains one leucine residue, and was detected using MALDI-TOFMS, as a singly charged species at $m / z 1325.6[\mathrm{M}+\mathrm{H}]^{+1}$. The $\mathrm{A} \beta_{6-16}$ fragment has a nominal mass of $1335.7 \mathrm{D}$, does not contain a leucine residue, and was detected as a singly charged species at $\mathrm{m} / \mathrm{z} 1336.7 \mathrm{D}[\mathrm{M}+\mathrm{H}]^{+1}$. MALDI-TOF-MS analysis identified the $\mathrm{A} \beta_{17-28}$ peptide fragment in tryptic digests of $\mathrm{A} \beta$ isolated from cells grown in the presence of naturally abundant ${ }^{13} \mathrm{C}$ -

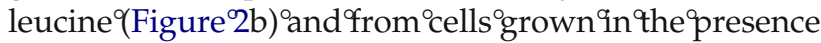
of ${ }^{13} \mathrm{C}_{6}$-leucine ${ }^{\circ}$ (Figure ${ }^{\circ} 2 \mathrm{c}$ ). ${ }^{\circ}$ This ${ }^{\circ}$ confirmed $^{\circ}$ that ${ }^{\circ}$ neuroglioma cells incorporated ${ }^{13} \mathrm{C}_{6}$-leucine into the predicted $\mathrm{A} \beta$ fragment, resulting in the expected $6 \mathrm{D}$ shift in $\mathrm{A} \beta_{17-28}$ peptide, and that this high level of ${ }^{13} \mathrm{C}_{6}$ leucine incorporation could be easily detected using MALDI-TOF-MS. This confirmed the specificity of the immunoprecipitation techniques in CSF and cell media and the ability to qualitatively identify labeled and unlabeled $\mathrm{A} \beta$ peptides.

After the isolation and detection of labeled and unlabeled $\mathrm{A} \beta$, the amount of labeled and unlabeled $\mathrm{A} \beta_{17-28}$ peptides was quantified using LC-ESI-tandem MS with quantitation of the full-scan tandem MS ions. The product ions detected by tandem mass spectrometry specifically identified the amino acid sequence for the labeled peptides based on the signature mass plus $6 \mathrm{D}$. This provided a highly specific "fingerprint" of the $\mathrm{A} \beta_{17-28}$ in both labeled and unlabeled forms. The tandem MS confirmed the expected amino acid sequence for $\mathrm{A} \beta_{17-28}$, and the mass spectra signal intensities were used to quantify the amount of labeled/unlabeled leucine in $\mathrm{A} \beta_{17-28^{\circ}}$ (Figure $3 \mathrm{a}$ ).

\section{Calculation of the Ratio of Labeled to Unlabeled Peptide}

To assess the ratio of labeled to unlabeled $A \beta$, the signal intensities from the product ions obtained in the tandem MS experiments were used to quantify the ratio of labeled to unlabeled $\mathrm{A} \beta_{17-28}$. The tandem MS spectra were averaged over the time that $\mathrm{A} \beta$ eluted from the LC column (number of tandem MS scans = 5) for both labeled and unlabeled tandem MS spectra. Each average intensity measurement was exported to an Excel spreadsheet where the masses of the expected $\mathrm{A} \beta$ tandem MS ions were matched and the tandem MS ion signal intensities were summed. The labeled/unlabeled ratio was derived by dividing the total tandem MS ion intensities, detected in the labeled spectra, by the total tandem MS ion intensities, in the unlabeled spectra, using a custom-written Microsoft Excel spreadsheet. Accuracy and precision were tested by generating a standard curve from serial dilutions of ${ }^{13} \mathrm{C}_{6}$-leucine labeled ${ }^{\circ}$ and $^{\circ}$ unlabeled $^{\circ} \mathrm{A} \beta^{\circ}$ formed ${ }^{\circ}$ in $^{\circ}$ vitro $^{\circ}$ (Figure ${ }^{\circ} 3 \mathrm{c}$ ).
The linear fit, from a range of 0 to $20 \%$ labeled $\mathrm{A} \beta$ serial dilution standard curve, had an $\mathrm{R}^{2}$ value of 0.98 and slope of 1.08. Alternative quantitation techniques were evaluated, and included, using the parent ion-signal intensities and the MALDI-TOF-MS spectra signal intensities. However, the sensitivity and specificity of these quantitative methods were inferior to those achieved using the signal intensities of tandem MS product ions. Specifically, labeled precursor ions were difficult to detect in the TIC or base peak MS scans above ${ }^{9}$ aseline ${ }^{9}{ }^{2}{ }^{9}$ (Figure $3 \mathrm{~b}$ ) ${ }^{\circ}$ and ${ }^{\circ}$ produce ${ }^{\circ}$ erroneous values $(10 \%$ for a $2.5 \%$ labeled standard). However, they were easily detected and their signal intensities were ${ }^{\circ}$ quantified ${ }^{\circ}$ by $^{\circ}$ tandem ${ }^{\circ} \mathrm{MS}^{\circ}$ analysis ${ }^{\circ}$ (Figure ${ }^{\circ}$ ). ${ }^{\circ}$ We concluded that $\mathrm{A} \beta$ can be labeled in vitro, and the amount of labeling can be quantitated accurately and precisely using LC-ESI-tandem MS.

\section{In Vivo Labeling and Quantitation}

Ten young, healthy human volunteers were enrolled in a metabolism study of $\mathrm{A} \beta$ kinetics to determine the production $^{\circ}$ and $^{\circ}$ clearance $^{\circ}$ rate $^{\circ}$ of ${ }^{\circ} \mathrm{A} \beta^{\circ}[13] .{ }^{\circ}$ The ${ }^{\circ}$ results indicate that this novel technique provided plausible in vivo $\mathrm{A} \beta$ protein production and clearance rates. We further validate the in vivo method by quantifying two $\mathrm{A} \beta$ production rates and a clearance rate in a middleaged (40-60 years old) healthy research participant during a ${ }^{13} \mathrm{C}_{6}$-leucine infusion, followed by the infusion of a second stable isotope-labeled amino acid $\left({ }^{13} \mathrm{C}_{6}\right.$ phenylalanine) in the same participant. We hypothesized that both tracers would provide similar estimates for in vivo $A \beta$ production rates. We intravenously administered a primed $(2 \mathrm{mg} / \mathrm{kg}$ bolus over $10 \mathrm{~min})$ constant ${ }^{13} \mathrm{C}_{6}$-leucine $\left(2 \mathrm{mg} \mathrm{kg}^{-1} \mathrm{~h}^{-1}\right)$ infusion for the first $9 \mathrm{~h}$ of the study, stopped the ${ }^{13} \mathrm{C}_{6}$-leucine infusion at $9 \mathrm{~h}$, and intravenously administered a primed $(3 \mathrm{mg} / \mathrm{kg}$ bolus over $10 \mathrm{~min})$, constant ${ }^{13} \mathrm{C}_{6}$-phenylalanine $(3 \mathrm{mg}$ $\mathrm{kg}^{-1} \mathrm{~h}^{-1}$ ) infusion from 16 to $25 \mathrm{~h}$. CSF samples $(6 \mathrm{~mL})$ were obtained from an indwelling lumbar catheter every hour from 0 to $36 \mathrm{~h}$.

We used GC-MS to quantify ${ }^{13} \mathrm{C}_{6}$ precursor amino acid enrichment in several accessible pools; $\mathrm{CSF}^{13} \mathrm{C}_{6}$ leucine and ${ }^{13} \mathrm{C}_{6}$-phenylalanine, plasma ${ }^{13} \mathrm{C}_{6}$-leucine, ${ }^{13} \mathrm{C}_{6}$-KIC, and ${ }^{13} \mathrm{C}_{6}$-phenylalanine. The labeled amino acid ratio was calculated as the average of the CSF labeled to unlabeled ratio amino acid as measured by GC-MS over the hours during infusion (hours 1 to 9 for leucine and hours 17 to 25 for phenylalanine). The average labeled CSF leucine $=11.5 \%$, plasma leucine $=$ $16.4 \%$, plasma $\mathrm{KIC}=12.7 \%$, CSF phenylalanine $=$ $22.3 \%$, and plasma phenylalanine $=26.9 \%$.

$\mathrm{A} \beta$ was immunoprecipitated from CSF, digested with trypsin, and ${ }^{13} \mathrm{C}_{6}$-leucine and ${ }^{13} \mathrm{C}_{6}$-phenylalanine abundances in $\mathrm{A} \beta_{17-28}$ were detected and quantified without $^{\circ}$ significant $^{\circ}$ interference ${ }^{\circ}$ (Figure ${ }^{\circ} 4 \mathrm{a}^{\circ}$ and ${ }^{\circ}$ b). The calculated $\mathrm{A} \beta$ FSRs were similar, accounting for the twofold higher ${ }^{13} \mathrm{C}_{6}$-phenylalanine enrichment in the CSF precursor during the infusion and the 
b-ions 213.2 $360.2 \quad 507.3 \quad 578.3 \quad 707.4 \quad 822.4 \quad 921.5 \quad 978.5 \quad 1065.51179 .6$
LV
$\mathrm{F}$
A E
D V
G
$\mathrm{S} \quad \mathrm{N} \quad \mathrm{K}$

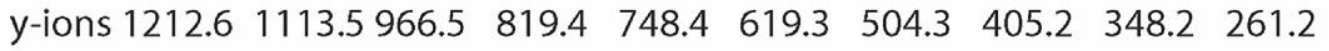

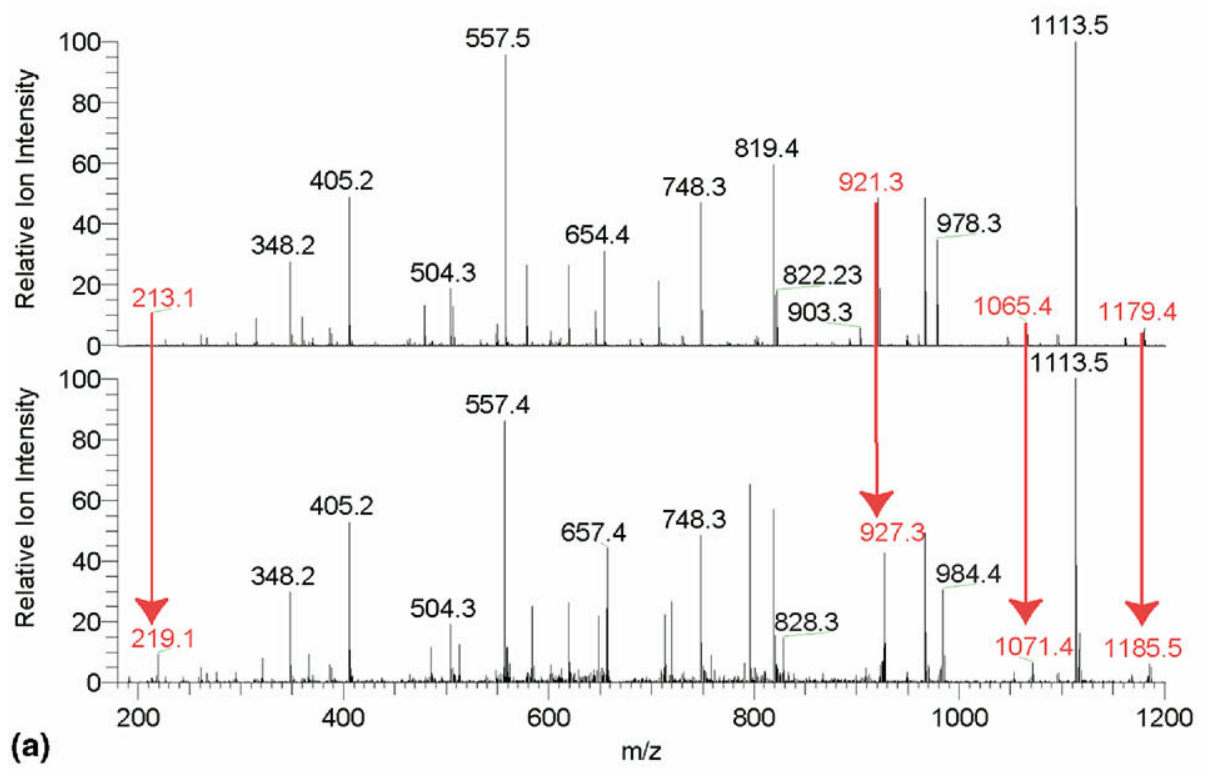

(a)

$\begin{array}{cllllllllll}\text { b-ions 213.2 } & 360.2 & 507.3 & 578.3 & 707.4 & 822.4 & 921.5 & 978.5 & 1065.5 & 1179.6 & \\ \text { LV } & \text { F } & \text { F } & \text { A } & \text { E } & \text { D } & \text { V } & \text { G } & \text { S } & \text { N } & \text { K } \\ \text { y-ions 1212.6 } & 1113.5 & 966.5 & 819.4 & 748.4 & 619.3 & 504.3 & 405.2 & 348.2 & 261.2 & \end{array}$

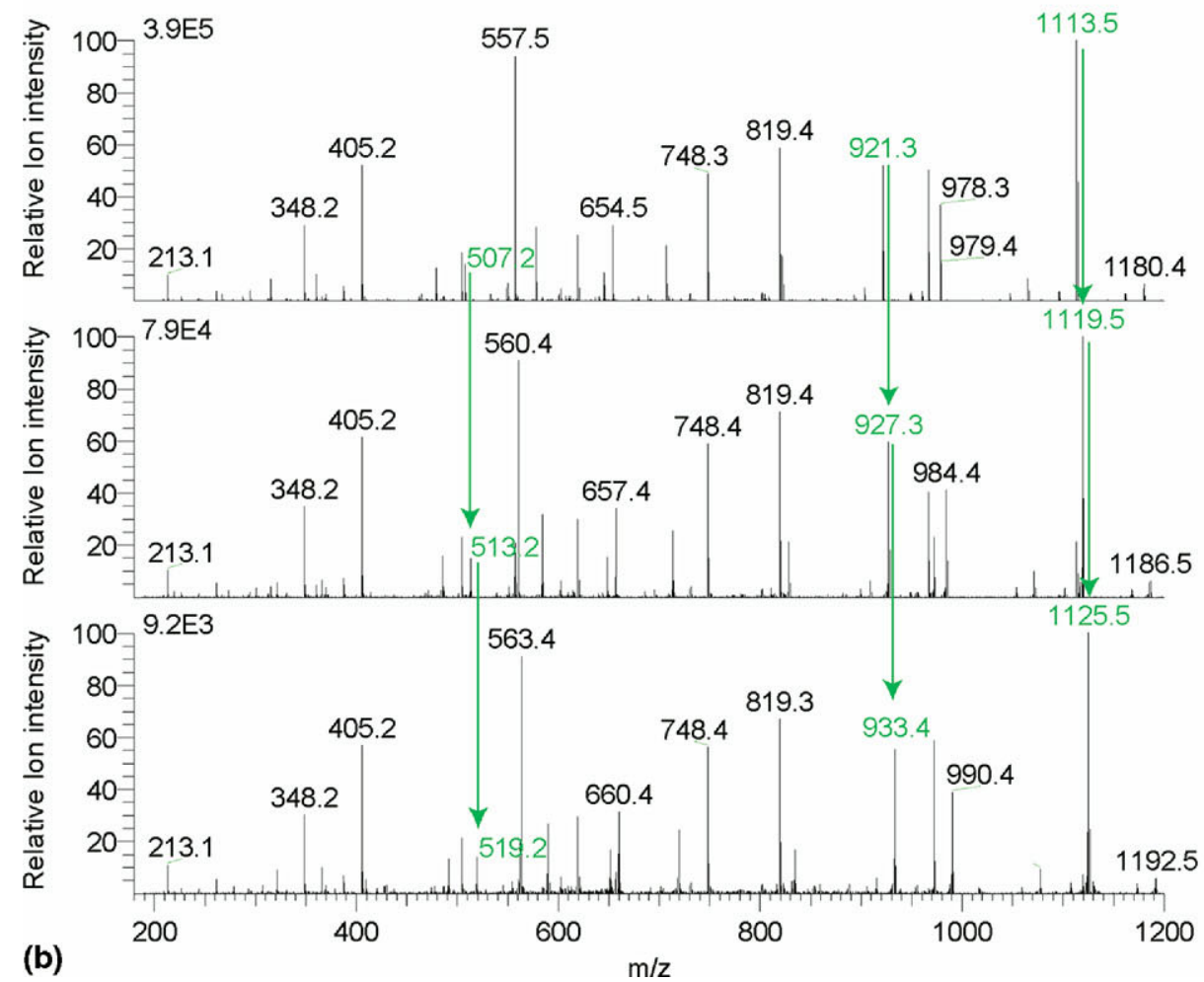

Figure 4. LTQ quantitation of tandem mass spectra of $\mathrm{A} \beta$ from human in vivo labeling with two amino acids. (a) Tandem MS spectra of $\mathrm{A} \beta_{17-28}$ from human CSF $13 \mathrm{~h}$ after in vivo ${ }^{13} \mathrm{C}_{6}$-leucine labeling demonstrate unlabeled $\mathrm{A} \beta_{17-28}$ tandem MS ions (top) and labeled $\mathrm{A} \beta_{17-28}$ tandem MS ions (bottom). The leucine containing tandem MS ions demonstrate the additional six Dalton label, as shown by arrows to leucine-containing ions. (b) Tandem MS spectra of $\mathrm{A} \beta_{17-28}$ from human CSF $12 \mathrm{~h}$ after in vivo labeling with ${ }^{13} \mathrm{C}_{6}$-phenylalanine demonstrate unlabeled ions (top), singly labeled ions (middle), and doubly labeled ions (bottom), as shown by arrows to phenylalanine-containing ions. 


\section{slope $=0.55 \pm 0.03, \mathrm{CSF}^{13} \mathrm{C}_{6}$-leucine $=11.5 \%$ FSR $=$ slope $\div$ precursor $=4.8 \% / \mathrm{hr}$ $\mathrm{FCR}=$ slope In $(\mathrm{TTR})=3.9 \% / \mathrm{hr}$}

(a)

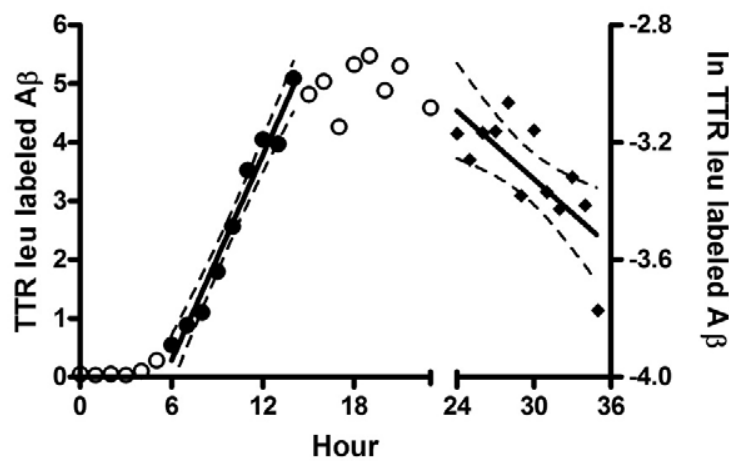

slope $=1.3 \pm 0.12, \mathrm{CSF}^{13} \mathrm{C}_{6}$-phenylalanine $=22.3 \%$ FSR $=$ slope $\div$ precursor $=5.8 \% / \mathrm{hr}$

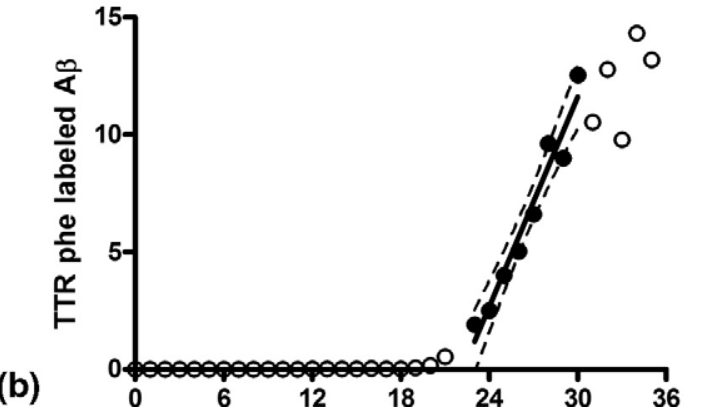

Figure 5. Two sequential measurements of fractional synthesis rate of $A \beta$ in the same participant. The ratio of labeled $A \beta$ to unlabeled $A \beta$ over $36 \mathrm{~h}$ is shown for a single participant who was intravenously given ${ }^{13} \mathrm{C}_{6}$-leucine for 0 to $9 \mathrm{~h}$, followed by phenylalanine given from 16 to $25 \mathrm{~h}$ of the study. Cerebrospinal fluid was collected hourly during and after labeling for a total of $36 \mathrm{~h}$. Each hourly sample was immunoprecipitated for $\mathrm{A} \beta$, trypsin digested, and analyzed for percentage leucine- and phenylalanine-labeled $\mathrm{A} \beta$. Note the rapid increase in leucine-labeled $\mathrm{A} \beta$ to plateau at $12 \mathrm{~h}$ and a subsequent decline in labeled $\mathrm{A} \beta$ after $24 \mathrm{~h}$. There is no detectable phenylalanine labeling until hour 20, followed by a rapid rise to plateau. (a) $\mathrm{A} \beta_{17-28}$ labeled leucine tandem MS ions were quantified excluding ${ }^{13} \mathrm{C}_{6}$-phenylalanine-containing ions and plotted over $36 \mathrm{~h}$. Leucine-labeled ions are detected $5 \mathrm{~h}$ after onset of labeling. FSR was calculated using the slope of the linear regression shown divided by the ${ }^{13} \mathrm{C}_{6}$-leucine enrichment in CSF. (b) ${ }^{13} \mathrm{C}_{6}$-phenylalanine-labeled $\mathrm{A} \beta_{17-28}$ tandem $\mathrm{MS}$ ions were quantified excluding ${ }^{13} \mathrm{C}_{6}$-leucine-containing ions and plotted over $36 \mathrm{~h}$ from the same tandem MS data files as in (a). There are no detectable phenylalanine-labeled ions during peak leucinelabeled A $\beta$ times $(5-20 \mathrm{~h})$. Phenylalanine-labeled ions are detected $5 \mathrm{~h}$ after onset of ${ }^{13} \mathrm{C}_{6}$-phenylalanine labeling. FSR was calculated using the slope of the linear regression shown divided by the ${ }^{13} \mathrm{C}_{6}$-phenylalanine enrichment in CSF.

twofold greater slope of the ${ }^{13} \mathrm{C}_{6}$-phenylalanine incorporation into $\mathrm{A} \beta_{17-28}$ versus time curves compared to leucine. The $\mathrm{A} \beta$ FSR was $4.8 \% / \mathrm{h}$ as measured by ${ }^{13} \mathrm{C}_{6}$-leucine-labeled $\mathrm{A} \beta$ and $5.8 \% / \mathrm{h}$ from ${ }^{13} \mathrm{C}_{6}$ phenylalanine-labeled ${ }^{\circ} \mathrm{A} \beta^{\circ}$ (Figure $^{\circ} 5$ ). ${ }^{\circ}$ The $^{\circ} \mathrm{A} \beta^{\circ} \mathrm{FCR}$ was $3.9 \% / \mathrm{h}$ as measured by ${ }^{13} \mathrm{C}_{6}$-leucine-labeled $\mathrm{A} \beta$ and could not be measured from ${ }^{13} \mathrm{C}_{6}$-phenylalaninelabeled $\mathrm{A} \beta$ because of only $36 \mathrm{~h}$ of sampling.

\section{Discussion}

We describe a method to quantify low-level stable isotope-labeled amino acid incorporation into a lowabundance (fmol) cerebrospinal fluid protein $(\mathrm{A} \beta)$, based on immunoprecipitation of the protein and tandem MS to quantify the abundance of ${ }^{13} \mathrm{C}$-labeled amino acid residues in tryptic peptides. This novel technique has been used to quantify human $\mathrm{A} \beta$ production and clearance rates. The technique is reproducible because two different stable isotope-labeled amino acids provided similar estimates of human $\mathrm{A} \beta$ production rates. The technique can be adapted to simultaneously quantify any/several proteins produced and degraded in vitro or in vivo systems. The technique is robust because it can be used to quantify production and clearance for any protein that can be isolated (not necessarily to purity) from a biological fluid and provides the advantage of confirming the protein/peptide identity because the amino acid sequence is derived from the tandem MS ions. Most important, perhaps, this in vivo approach can be used to quantify alterations in low-abundance protein production and clearance rates that may underlie the pathogenesis of human disease, to identify and quantify potential biomarkers for disease, and to evaluate the efficacy of proposed disease-modifying therapies. Potentially, this general approach can be applied to quantify the kinetics of other macromolecules produced in the CNS, including lipids, carbohydrates, and inflammatory markers, although care must be taken to select an appropriate stable isotope-labeled precursor that crosses the bloodbrain barrier and does not enter rapidly recycling metabolic processes. In addition, the method may provide quantitative and comparative kinetic information about proteins that exist in multiple accessible compartments (blood, CSF, or urine).

Established stable isotope tracer methods and mass spectrometric analytical approaches exist (GC-MS and gas isotope ratio MS) for quantifying the in vivo synthesis and clearance rates for abundant (microgram to milligram quantities) proteins, such as albumin, apolipoprotein ${ }^{\circ} \mathrm{B},{ }^{\circ}$ myosin, ${ }^{\circ}$ and $^{\circ}$ surfactant $^{\circ}\left[11,{ }^{2} 0^{\circ}-24\right] .{ }^{\circ}$ Newer methods using SDS-PAGE and MALDI-TOF can quantify multiple in vivo protein synthesis and clearance rates ${ }^{\circ}[25]^{\circ}$ or $^{\circ}$ in $^{\circ}$ vitro $^{\circ}$ prokaryotic ${ }^{\circ}$ synthesis $^{\circ}$ to $^{\circ}$ degradation $^{\circ}$ ratios $^{\circ}[26]^{\circ}{ }^{\circ}$ These ${ }^{\circ}$ advances ${ }^{\circ}$ have ${ }^{\circ}$ helped ${ }^{\circ}$ automate and extend the capabilities for quantitative proteomics. Although accurate, these methods were not suitable for a low-abundance (fmol) protein such as $A \beta$. We have exploited the recent advances in LC-ESI-tandem MS to further refine these methods so that sensitive, specific, accurate $( \pm 1 \%)$, and reliable quantitation of stable isotope abundance in isolates of very low abundance proteins/peptides (fmol) can be achieved. The SILT approach demonstrates significantly higher sensitivity for total amount of protein (fmol), percentage labeling (accurate to within 1\% on a single analysis), and automation by using LC-MS/MS without the need for 
protein separation by gel electrophoresis. We demonstrate this proof-of-principle by quantifying the in vivo kinetic rates for a biologically relevant protein that is involved in the pathogenesis of AD. Another advantage of this approach is that during the stable isotope labeling experiment, any/all proteins that are being produced are labeled simultaneously. This approach and quantitative mass spectrometry provide the potential to simultaneously quantify multiple protein production and clearance rates in the same samples by measuring percentage labeling of many peptides using SILT analysis. The only requirements are that at least one peptide with a potential labeled amino acid is quantified. For the $\mathrm{A} \beta$ peptide detected in this study, the labeled leucine was located on the $\mathrm{N}$-terminus, and thus all $\mathrm{b}$-ions were labeled and y-ions were unlabeled. Because the phenylalanine residues were located in central positions, some b- and some y-ions were labeled, whereas others were unlabeled. The SILT algorithm separately summed labeled MS2 ions (those containing the amino acid that could potentially be labeled) and unlabeled MS2 ions before calculating the ratio. The labeling can occur at any position and, after the peptide sequence is determined from the tandem MS spectra, the MS2 ions that are expected to be labeled, and thus mass shifted, are predicted from the sequence and can be used in the calculation of labeled to unlabeled ratio. The measurement and calculation are not dependent on amino acid location in the peptide sequence.

We chose to use the ${ }^{C S F}{ }^{13} \mathrm{C}_{6}$-leucine and ${ }^{13} \mathrm{C}_{6}$ phenylalanine enrichment to represent the precursor pool enrichment for $\mathrm{A} \beta$ synthesis in our analysis based on several facts. CSF is within the central nervous system, and should reflect brain tissue extracellular enrichment better than plasma. Also, the $\mathrm{CSF}^{13} \mathrm{C}_{6}$ leucine enrichment was similar to plasma ${ }^{13} \mathrm{C}_{6}$ - KIC enrichment and KIC likely reflects the intracellular pool enrichment better than plasma leucine. Because there are two phenylalanine residues in the $\mathrm{A} \beta$ peptide fragment analyzed, an elegant precursor enrichment measurement, mass isotopomer distribution analysis (MIDA), may theoretically be used to measure the precursor ${ }^{\circ}$ enrichment ${ }^{\circ}$ directly ${ }^{\circ}[27] .{ }^{\circ}$ However, ${ }^{\circ}$ because there is only one leucine present in this peptide fragment, MIDA could not be used with the leucine tracer and would not be suitable for comparison of leucine and phenylalanine precursor enrichments.

Protein quantitation using tandem MS is well established based on extracted ion chromatograms, which quantitate the MS parent ions, as opposed to the MS2 ions'used in this'study [28]. Using MS precursor'ions for quantitation, a change of 30 to $50 \%$ in protein amounts can be detected. The tandem MS analysis used here is different because it strongly suggests that LC-ESItandem MS can provide very sensitive $(\sim 1 \%)$ and accurate $( \pm 1 \% \mathrm{SD})$ quantitation of stable isotope enrichment (isotope ratios) in very low abundant proteins/ peptides. The minimum level of protein we have analyzed by SILT has been $33 \mathrm{fmol} \mathrm{A} \beta$ before immuno- precipitation and trypsin digest with a sensitivity of $1 \%$ labeling and a linear fit of the standard curve with an $\mathrm{R}^{2}=0.99$. This level of sensitivity was not possible through use of precursor MS1 quantitation. For example, the labeled $A \beta$ could not be detected above baseline in $^{\circ}$ the ${ }^{\circ} \mathrm{MS1}^{\circ} \operatorname{scan}^{\circ}$ (Figure $3 \mathrm{~b}$ )..$^{\circ}$ Among ${ }^{\circ}$ other ${ }^{\circ}$ reasons, ${ }^{\circ}$ this is possible because we quantified the tandem MS signal intensities for $b$ - and $y$-series ions, for both the labeled and unlabeled $\mathrm{A} \beta_{17-28}$ peptide. This "summing" of the tandem MS ion signal intensities effectively increased both the sensitivity and specificity of the isotope ratio quantitation.

\section{Conclusion}

SILT offers a way to measure protein isotope ratios in vitro and in vivo for a large number of proteins that were previously too low in abundance for quantitative isotope abundance analysis. The technique may be applied for total protein quantitation using stable isotope labeled standards or for isotope ratios in determining protein production and clearance rates. This may lead to new information about the physiology and pathophysiology of biologically and medically relevant proteins or other macromolecules.

\section{Acknowledgments}

This work was supported by grants from the American Academy of Neurology Foundation, National Institute on Aging Grant K08 AG-027091-01 and Alzheimer's Disease Research Centers Grant P50 AG-05681, Blanchette Hooker Rockefeller Foundation, GCRC (MO1 RR00036), Mass Spectrometry Resource (RR000954), the Clinical Nutrition Research Unit (DK056341), and the Diabetes Research and Training Center (DK020579). The authors are grateful to the participant for his time, to Cambridge Isotope Laboratories (Ronald Trolard) for providing the ${ }^{13} \mathrm{C}_{6}$-phenylalanine, to Eli Lilly for providing m266 antibody, and to Dr. Robert Swarm for providing support for lumbar catheterization.

\section{References}

1. Andersen, J. S.; Lam, Y. W.; Leung, A. K.; Ong, S. E.; Lyon, C. E.; Lamond, A. I.; Mann, M. Nucleolar Proteome Dynamics. Nature 2005, $433,77-83$.

2. Zhang, G.; Neubert, T. A. Automated Comparative Proteomics Based on Multiplex Tandem Mass Spectrometry and Stable Isotope Labeling. Mol. Cell. Proteomics 2006, 5, 401-411.

3. Ong, S. E.; Blagoev, B.; Kratchmarova, I.; Kristensen, D. B.; Steen, H. Pandey, A.; Mann, M. Stable Isotope Labeling by Amino Acids in Cell Culture, SILAC, as a Simple and Accurate Approach to Expression Proteomics. Mol. Cell. Proteomics 2002, 1, 376-386.

4. Wu, C. C.; MacCoss, M. J.; Howell, K. E.; Matthews, D. E.; Yates, J. R., 3rd. Metabolic Labeling of Mammalian Organisms with Stable Isotopes for Quantitative Proteomic Analysis. Anal. Chem. 2004, 76, 4951-4959.

5. Jaleel, A.; Nehra, V.; Persson, X. M.; Boirie, Y.; Bigelow, M.; Nair, K. S. In Vivo Measurement of Synthesis Rate of Multiple Plasma Proteins in Humans. Am. J. Physiol. Endocrinol. Metab. 2006, 291, E190-E197.

6. Wolfe, R. R. Regulation of Skeletal Muscle Protein Metabolism in Catabolic States. Curr. Opin. Clin. Nutr. Metab. Care 2005, 8, 61-65.

7. Wolfe, R. R. Regulation of Muscle Protein by Amino Acids. J. Nutr. 2002, 132, 3219S-3224S

8. San Pietro, A.; Rittenberg, D. A Study of the Rate of Protein Synthesis in Humans. II. Measurement of the Metabolic Pool and the Rate of Protein Synthesis. J. Biol. Chem. 1953, 201, 457-473.

9. Balagopal, P.; Rooyackers, O. E.; Adey, D. B.; Ades, P. A.; Nair, K. S. Effects of Aging on In Vivo Synthesis of Skeletal Muscle Myosin Heavy-chain and Sarcoplasmic Protein in Humans. Am. J. Physiol. Endocrinol. Metab. 1997, 273, E790-E800. 
10. Yarasheski, K. E. Exercise, Aging, and Muscle Protein Metabolism. J. Gerontol. A Biol. Sci. Med. Sci. 2003, 58, M918-M922.

11. Elias, N.; Patterson, B. W.; Schonfeld, G. In Vivo Metabolism of ApoB, ApoA-I, and VLDL Triglycerides in a Form of Hypobetalipoproteinemia Not Linked to the ApoB Gene. Arterioscler. Thromb. Vasc. Biol. 2000, 20, 1309-1315.

12. Podlisny, M. B.; Lee, G.; Selkoe, D. J. Gene Dosage of the Amyloid Beta Precursor Protein in Alzheimer's Disease. Science 1987, 238, 669-671.

13. Bateman, R. J.; Munsell, L. Y.; Morris, J. C.; Swarm, R.; Yarasheski, K. E.; Holtzman, D. M. Human Amyloid-beta Synthesis and Clearance Rates as Measured in Cerebrospinal Fluid In Vivo. Nat. Med. 2006, 12, 856-861.

14. Murphy, M. P.; Uljon, S. N.; Fraser, P. E.; Fauq, A.; Lookingbill, H. A.; Findlay, K. A.; Smith, T. E.; Lewis, P. A.; McLendon, D. C.; Wang, R.; Golde, T. E. Presenilin 1 Regulates Pharmacologically Distinct Gammasecretase Activities. Implications for the Role of Presenilin in Gammasecretase Cleavage. J. Biol. Chem. 2000, 275, 26277-26284.

15. DeMattos, R. B.; Bales, K. R.; Cummins, D. J.; Dodart, J. C.; Paul, S. M.; Holtzman, D. M. Peripheral Anti-A Beta Antibody Alters CNS and Plasma A Beta Clearance and Decreases Brain A Beta Burden in a Mouse Model of Alzheimer's Disease. Proc. Natl. Acad. Sci. USA 2001, 98, 8850-8855.

16. Yarasheski, K. E.; Smith, S. R.; Powderly, W. G. Reducing Plasma HIV RNA Improves Muscle Amino Acid Metabolism. Am. J. Physiol. Endocrinol. Metab. 2005, 288, E278-E284.

17. Smith, Q. R.; Momma, S.; Aoyagi, M.; Rapoport, S. I. Kinetics of Neutral Amino Acid Transport across the Blood-Brain Barrier. J. Neurochem. 1987, 49, 1651-1658.

18. Krijgsveld, J.; Ketting, R. F.; Mahmoudi, T.; Johansen, J.; Artal-Sanz, M.; Verrijzer, C. P.; Plasterk, R. H.; Heck, A. J. Metabolic Labeling of C. elegans and D. melanogaster for Quantitative Proteomics. Nat. Biotechnol. 2003, 21, 927-931.

19. Wang, R.; Sweeney, D.; Gandy, S. E.; Sisodia, S. S. The Profile of Soluble Amyloid Beta Protein in Cultured Cell Media. Detection and Quantification of Amyloid Beta Protein and Variants by Immuno-
precipitation-Mass Spectrometry. J. Biol. Chem. 1996, 271, 31894-31902.

20. Patterson, B. W. Use of Stable Isotopically Labeled Tracers for Studies of Metabolic Kinetics: An Overview. Metabolism 1997, 46, 322-329.

21. Yarasheski, K. E.; Smith, K.; Rennie, M. J.; Bier, D. M. Measurement of Muscle Protein Fractional Synthetic Rate by Capillary Gas Chromatography/Combustion Isotope Ratio Mass Spectrometry. Biol. Mass Spectrom. 1992, 21, 486-490.

22. Hasten, D. L.; Morris, G. S.; Ramanadham, S.; Yarasheski, K. E. Isolation of Human Skeletal Muscle Myosin Heavy Chain and Actin for Measurement of Fractional Synthesis Rates. Am. J. Physiol. Endocrinol. Metab. 1998, 275, E1092-E1099.

23. Merchak, A.; Patterson, B. W.; Yarasheski, K. E.; Hamvas, A. Use of Stable Isotope Labeling Technique and Mass Isotopomer Distribution Analysis of [(13)C]Palmitate Isolated from Surfactant Disaturated Phospholipids to Study Surfactant In Vivo Kinetics in a Premature Infant. J. Mass Spectrom. 2000, 35, 734-738.

24. Schulte, J. N.; Yarasheski, K. E. Effects of Resistance Training on the Rate of Muscle Protein Synthesis in Frail Elderly People. Int. J. Sport Nutr. Exerc. Metab. Suppl. 2001, 11, S111-S118.

25. Doherty, M. K.; Whitehead, C.; McCormack, H.; Gaskell, S. J.; Beynon, R. J. Proteome Dynamics in Complex Organisms: Using Stable Isotopes to Monitor Individual Protein Turnover Rates. Proteomics 2005, 5, $522-533$.

26. Cargile, B. J.; Bundy, J. L.; Grunden, A. M.; Stephenson, J. L., Jr. Synthesis/Degradation Ratio Mass Spectrometry for Measuring Relative Dynamic Protein Turnover. Anal. Chem. 2004, 76, 86-97.

27. Papageorgopoulos, C.; Caldwell, K.; Shackleton, C.; Schweingrubber, H.; Hellerstein, M. K. Measuring Protein Synthesis by Mass Isotopomer Distribution Analysis (MIDA). Anal. Biochem. 1999, 267, 1-16.

28. Li, X. J. Zhang, H.; Ranish, J. A.; Aebersold, R. Automated Statistical Analysis of Protein Abundance Ratios from Data Generated by StableIsotope Dilution and Tandem Mass Spectrometry. Anal. Chem. 2003, 75, 6648-6657. 